\title{
Phenotypic Basis for a Feeding Change in an Insular Population of Garter Snakes
}

\author{
MARTIN G. GREENWELL \\ MARTHA HALL \\ OWEN J. SEXTON \\ Department of Biology \\ Washington University \\ St. Louis, Missouri \\ and University of Michigan Biology Station \\ Pellston, Michigan
}

\begin{abstract}
Predation on birds, an unusual behavior for the common garter snake (Thamnophis sirtalis), has been observed and documented in an insular garter snake population. Feeding preference tests were performed on naive neonatal snakes and experienced adults from both the island test population and a nearby mainland control population. No significant preference for birds as a prey item was found for either neonates or adults from either population. Therefore, neither a genetic nor an ontogenetic basis for the observed behavior was demonstrable. Birds tainted with a piscine odor, however, elicited a positive feeding response from adult snakes from both geographical sources. We propose that the observed behavior in the field is a result of learning to exploit an abundant, readily available resource already in the predator's repertoire.
\end{abstract}

The garter snake, Thamnophis sirtalis, has been shown to be a generalized predator, feeding upon earthworms, leeches, snails, snakes, amphibians, small mammals, small birds, and carrion (Carpenter, 1952; Fitch, 1965; Gregory, 1978; Hamilton, 1951). Within this dietary array, however, earthworms and amphibians are eaten preferentially. Indeed, the frequency with which mammals and birds were eaten was quite low (Carpenter, 1952; Fitch, 1965; Gregory, 1978; Hamilton, 1951; Lagler \& Salyer, 1945). Yet on certain islands of the Beaver Archipelago in Lake Michigan, T. sirtalis has been observed preying extensively on nestlings in the breeding colonies of the common tern, Sterna hirundo, and other colonial larids (Cuthbert, 1982).

According to the equilibrium theory of island biogeography put forth by MacArthur and Wilson $(1963,1967)$, this expansion in the dietary niche of $T$. sirtalis could be a tesult of either an ecological shift or release. These theoretical changes could result from either a phenotypic or a genetic mechanism. Phenotypically, the insular snakes either may be learning to exploit abundant food resources (tern nestlings) already in their dietary repertoire, or are able to consume larger prey items (birds) because of ontogenetic change, i.e., increased body size. Genetically, the snakes could be subject to directional selection that would favor pre-existing, bird-eating alleles, or be subject to mutations including

Reprint requests should be sent to Dr. Owen J. Sexton, Box 1137, Department of Biology, Washington University, St. Louis, Missouri 63130, U.S.A.

Received for publication 15 October 1983

Revised for publication 7 February 1984

Developmental Psychobiology, 17(5):457-463 (1984)

(C) 1984 by John Wiley \& Sons, Inc. 
bird-eating that occurred after colonization of the island. The present paper seeks to distinguish between a phenotypic and a genetic basis for the observed feeding change in the insular garter snakes. This can be done through feeding preference comparisons between island adult and ingestively naive neonates and those of local mainland populations.

The reaction of precocial, ingestively naive neonates to a variety of prey items should provide insights into prey recognition independent of subsequent learned behavior. Burghardt (1969) has provided a technique for measuring initial feeding responses of naive neonates based upon vomeronasal chemoreception.

\section{Methods}

Fifteen adult $T$. sirtalis were collected from a mainland site (L), the University of Michigan Biological Station at Douglas Lake, Pellston, Michigan. Twenty-nine adult conspecifics were also collected from an island locale $(\mathrm{H})$, High Island of the Beaver Archipelago, located $35 \mathrm{~km}$ west of the western slope of the northern part of Michigan's lower peninsula. Both the $\mathrm{L}$ and $\mathrm{H}$ population samples were collected during July and August of 1980 and 1981. These samples were then transported to facilities at Washington University, St. Louis, Missouri, for testing. Upon arrival, the adult snakes were all individually marked by clipping ventral scutes at positions unique to each subject. These positions were recorded and correlated with each snake's geographical source. The adult snakes were individually housed in covered glass aquaria (sizes ranged from $30 \times 30 \times 20 \mathrm{~cm}$ to $35 \times 30 \times 30 \mathrm{~cm}$ ) and provided with adequate ventilation and water ad libitum. Sanitation of the enclosures was carried out on a daily basis. An artificial photophase of 12 hr was provided through fluorescent lighting. The snakes were fed large earthworms or goldfish twice weekly. Feeding of the adult snakes took place outside of their permanent enclosures to prevent neonates from being exposed to any feeding stimulus in their mothers' cages, thus precluding any biasing of the neonates' experimental feeding responses.

From the adults collected, $10 \mathrm{~L}$ and $8 \mathrm{H}$ females gave birth to $63 \mathrm{~L}$ and $47 \mathrm{H}$ young, respectively. All of the mainland neonates and 45 of the island neonates were tested $(2 \mathrm{H}$ young escaped). Postnatally, the young were immediately isolated from their mothers and put into covered glass aquaria. These neonates were grouped by litter and their enclosures were labelled as to the identity and geographical source of the mother. The date of birth was also recorded on the neonates' cages. The neonates were supplied with water ad libitum but were left unfed.

The testing of the young occurred between 1 and 6 days postpartum in order to minimize sample losses due to congenital defects. One hour prior to a testing sequence, each neonate was separated from its siblings and placed in a testing chamber. It was left undisturbed during this period so that it would become acclimated to its new enclosure. The testing chamber consisted of an opaque plastic box $(15 \mathrm{~cm}$ high $\times 15 \mathrm{~cm}$ wide $\times$ $35 \mathrm{~cm}$ long), which was covered by a section of cardboard. The section of cardboard had a rectangular area cut out so that the neonate could be observed during the test trials. Each neonate was subjected to a test series that consisted of the randomly ordered, sequential presentation of six surrogate prey items. Each surrogate prey item consisted of a Q-tip taped to the end of a 40-cm-long $\times$ 5-mm-diameter wooden dowel. The cotton tip was dipped in distilled water and rubbed over the surface of one of the prey items, which were kept frozen when not used in the testing. The prey items consisted of a tern embryo, an amphibian (Rana spp. larvae), an earthworm, a newborn mouse, and a fish (Lepomis cyanellus). A Q-tip dipped in distilled water served as a control and constituted 
the sixth prey item. Each surrogate prey was assigned a number $(0-5)$ which was maintained throughout the study. Choosing a surrogate prey item for a trial was facilitated by a random-number table.

Each trial within a series began with choosing at random a surrogate prey item and a 10-sec introductory period during which the randomly chosen swab was placed within 1 $\mathrm{cm}$ of the test subject's head. During this introductory period, no tongue flicks were recorded, so as to allow the neonate to overcome its initial alarm at the novel stimulus. After the introductory period, a 3-min test period ensued, during which the swab was kept within $1 \mathrm{~cm}$ of the subject's head and all tongue flicks were counted using a hand counter. After each 3-min test period, the total number of tongue flicks was recorded for each subject, as well as its given surrogate prey item. If no response was obtained within $30 \mathrm{sec}$ after presentation of the surrogate prey, the swab was gently touched to the snake's mouth. A totally unresponsive neonate was retested the following day. Each Q-tip swab was removed and discarded after the 3-min test period. No swab was ever reused, to prevent confounding the snake's response. No neonate was tested more than once on a particular prey species. The test trial was repeated with each of the five remaining prey items, a period of 1 min elapsing between each trial. After the series of six trials, one for each prey item, the neonate was returned to a clean, empty enclosure and fed an earthworm.

Burghardt (1969) demonstrated that the relative frequency of tongue flicks can be correlated to a snake's dietary preference in its natural feeding repertoire. Thus, by comparing the number of tongue flicks evinced by each neonate for every surrogate prey item in a sequence of trials, we could rank the prey items according to preference by each neonate. Therefore, for each individual, the prey item that stimulated the highest number of tongue flicks was ranked as most preferred. The prey item that evoked the secondhighest number of tongue flicks was ranked as the second most preferred and so on until the least preferred or sixth-ranked prey item. Thus, all five prey items and the water control were assigned a number rank. If two items were preferred equally, they were assigned a number that was the average of two sequential ranks, e.g., if fish and earthworm both were tied for rank 1 , they were given a rank of 1.5 as an average of 1 and 2 . From this ranking for each neonate from both $\mathrm{L}$ and $\mathrm{H}$, the total number of first ranks for each prey item was tabulated. Then, the proportion of first ranks for each prey item was calculated by dividing the total number of first ranks for a given prey item by the total possible number. As an example, there were 45 possible first ranks for $\mathrm{H}$ neonates since there were $45 \mathrm{H}$ neonates tested. The prey items were then ranked by frequency according to the ascending order of first-rank proportions. This was done separately for $\mathrm{H}$ and $\mathrm{L}$ neonates.

The adult snakes from $\mathrm{H}$ and $\mathrm{L}$ were subjected to presentations of whole thawed prey. This consisted of testing the adults for feeding responses to the five prey items [fish, amphibian, earthworm, mouse, bird (hatchlings of Coturnix quail were substituted for the tern embryos)] used in the neonate tests. These presentations occurred at a minimum of 4 days following the snake's most recent meal. In this test, an adult snake was placed in an isolated, previously cleaned 211.5-liter glass aquarium. The snake was then presented with a whole prey item for $10 \mathrm{~min}$. A positive response was recorded if the prey item was attacked and consumption initiated. If the response was negative, a live goldfish was presented as a hunger control. If either the test prey or the goldfish was consumed, the snake was left unfed for a minimum of 4 days. After the 4-day period, the adult snake was again tested with a different whole prey item. This was carried out until all five prey items were tested. If neither the test prey nor the hunger control was consumed, testing was resumed following a $1 / 4-\mathrm{hr}$ interim. By tabulating the number of 
whole prey items from each of the five food classes consumed by the adult snakes from both $\mathrm{H}$ and $\mathrm{L}$, the percentage of adults that consumed prey was calculated. This was done separately for both $\mathrm{H}$ and $\mathrm{L}$ adults.

\section{Results}

The preference ranking for the $45 \mathrm{H}$ neonates was in descending order: earthworm (24), amphibian (7), bird (6), fish (5), mouse (2), and water (1) (Fig. 1). For the $63 \mathrm{~L}$ neonates tested, the preference order was earthworm (25), bird (13), fish (10), amphibian (9), water (4), and mouse (2) (Fig. 1). Using the absolute numbers of first ranks for the four most preferred prey items, the chi-square contingency test showed that prey preferences for the two neonate classes did not very significantly $\left(\chi^{2}=2.35, d f=3, p=.50\right)$. Mouse and water were excluded as prey classes in the $\chi^{2}$ test owing to their very low preference.

From the whole prey tests for the $\mathrm{H}$ and $\mathrm{L}$ adults, the preferences, according to proportions of adults that consumed each prey item, were elucidated for both geographic locales (Fig. 2). All of the $11 \mathrm{~L}$ adults ate the ranid larvae. Numbers of $\mathrm{L}$ adults eating other prey were: earthworm (9), fish (6), mouse (2) and bird (0). The order for the 29 $\mathrm{H}$ adults was amphibian (23), earthworm (22), fish (17), bird (1), and mouse (1). Using the absolute numbers of adults that consumed prey in the three most preferred prey classes, the $\chi^{2}$ test revealed no significant difference in the feeding preferences of $\mathrm{H}$ and $\mathrm{L}$ adults $\left(\chi^{2}=2.67, d f=2, .70<p<.90\right)$. Mouse and bird were omitted as prey classes in the $\chi^{2}$ test because of their low preference ranking for both $H$ and $L$ adults.

Since adults were observed preying extensively on larid nestlings on High Island, the low score for bird consumption in $\mathrm{H}$ adults seemed puzzling. However, the $\mathrm{H}$ adults were not collected from the immediate vicinity of the tern colony but from about $.5-1 \mathrm{~km}$ distant. Hence, these subjects might not have had direct experience with nestling terns as a potential food item. The twelve adults remaining as of $1 / 15 / 82$ were retested for bird consumption and all subjects again rejected birds. Following a 4-day interval, however, the adults were again presented with whole bird carcasses; this time the carcasses were tainted with fish odor. In this novel test, 9 of the 12 snakes (including $1 \mathrm{~L}$ adult) proceeded to consume the birds. The remaining three snakes attacked the tainted carcasses

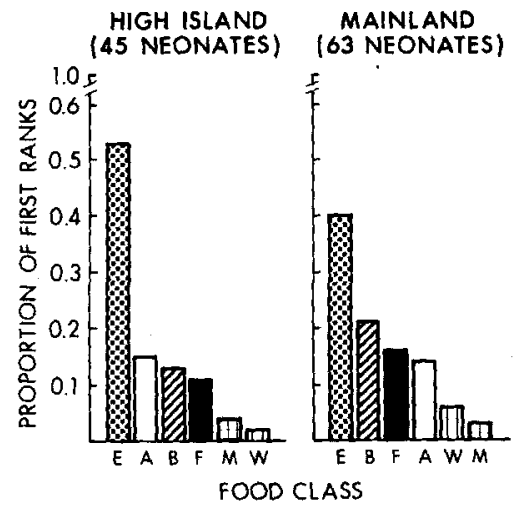

Fig. 1. The proportional frequency of positive response by tongue flicking of naive, neonatal common garter snakes (Thamnophis sirtalis) to a variety of potential prey items. $\mathrm{E}=$ earthworm; $\mathrm{A}=$ amphibian; $B=$ bird $; F=$ fish; $M=$ mouse; $W=$ water (control). 


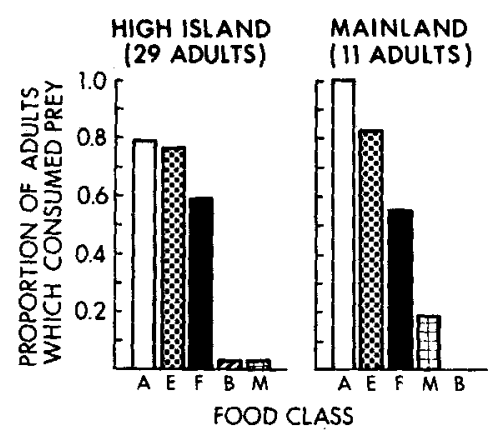

Fig. 2. The proportion of adult garter snakes that consumed or attacked a variety of potential prey. Abbreviations as in Figure 1.

and initiated consumption, but they were unable to ingest the birds, presumably due to size limitations.

\section{Discussion}

The $\chi^{2}$ test revealed no significant difference between the dietary preferences of the two neonate samples. More important, the $\mathrm{H}$ neonates showed no marked preference for birds as a prey item. Thus, at birth, $H$ neonates do not express genes for bird predation. It would seem, then, that the observed geographical variation of avian predation in $\mathrm{H}$ adults in the field has no prima facie genetic basis. Arnold's (1981a,b) work on Thamnophis elegans demonstrated that that species did show a genetic basis for its geographical variation in feeding behavior. The $\mathrm{H}$ neonates would obviously be precluded from preying on birds because of morphological constraints. Indeed, a snake the size of an earthworm might well be a likely prey item for a foraging gull or tern. The neonates' preference for earthworms is indicative of their adaptation to exploiting weak, easily handled prey items. In all, the lack of dietary variation in the two neonate samples tested indicates that, in the present case, the response of the isolated, naive conspecific subjects to a spectrum of prey is independent of the geographical source of the subjects.

The observed avian predation on High Island may be a function of ontogenetic changes that would allow exploitation of larger prey items by adult snakes. The physical barrier of size must surely play a role in determining the behavior of bird predation. Mushinsky, Hebrard, and Vodopich (1982) demonstrated the ontogenetic dietary changes in four sympatric species of Nerodia. In the present study, however, ontogenetic changes as a basis for the observed feeding anomaly seem unlikely for two reasons. First, there is little field evidence indicating avian predation by mainland $T$. sirtalis. Second, only 1 of the 40 adult snakes tested consumed an untainted bird carcass. It would seem that if ontogenetic change were a viable basis for the observed behavior in the field, more of the adult snakes would have evinced bird consumption on the basis of their size and maturity.

Although we found no evidence for an ontogenetic dietary shift to birds, there was evidence in both populations of an ontogenetic shift to fish and amphibian prey. Twentyfour of the $45 \mathrm{H}$ snakes (frequency $=.53$ ) and 25 of the $63 \mathrm{~L}$ young $(.40$ ) responded preferentially to earthworms over the other prey. Both sets of neonates responded relatively similarly to bird, amphibian and fish. Frequencies of highest preference for $\mathrm{H}$ snakes were: bird, .13, amphibian, .16, and fish, .11. Similar values for $\mathrm{L}$ snakes were: birds, .21, amphibians, .14, and fish, .16. The frequencies of first preference for both the water control and for mice were very low for all neonates. Seventy-six percent of the $\mathrm{H}$ 
adults and $82 \%$ of the $\mathrm{L}$ adults ate earthworms. However, $59 \%$ of the $\mathrm{H}$ adults ate fish, as did $54 \%$ of the $\mathrm{L}$ adults. All of the $\mathrm{L}$ adults and $79 \%$ of the $\mathrm{H}$ adults ate amphibians. Shifts to fish and amphibians by both populations of snakes could be accounted for by several mechanisms. One possible mechanism is an increase in body size, which would facilitate capture of larger, more active, and more irregularly shaped prey.

The basis of the behavior in these field observations, then, would seem to be behavioral. The snakes are most likely learning to exploit abundant sources of food already in their dietary repertoire. The role of learning is enhanced in the tests with whole bird carcasses tainted with fish odor. The fact that odor is the primary stimulus for foraging garter snakes to strike is well known (Chiszar, Taylor, Radcliffe, Smith, \& O'Connell, 1981). In the 12 snake test samples using the tainted carcass, a shift from $0 \%$ bird consumption to $75 \%$ bird consumption, and to $100 \%$ attack level is indeed notable. The behavior observed on High Island is probably the result of both the abundance and availability of colonial larid nestlings as well as the reinforcement of piscine odors in the nests themselves. In fact, larids are highly piscivorous. Their nests and presumably nestlings are strongly tainted with a fishy odor from uneaten fish carcasses, parental regurgitation, and fecal material. Thus, fish odors and nestling activity should both be very attractive to the foraging garter snake. The visual and olfactory components of garter snake feeding behavior has been demonstrated by Chiszar et al. (1981). The high attack level on fish by both sets of adults emphasizes the importance of fish scent in our proposed scheme.

Interspecific competitors may or may not influence avian predation by garter snakes on High Island. This factor is difficult to assess and is beyond the scope of this paper.

Bird predation by $T$. sirtalis on High Island could represent an ecological shift, since mainland populations do consume birds at a low frequency. Or, since larids tend to breed on islands, the exploitation of insular colonies may be indicative of an ecological release, through expansion into a niche dimension unfavorable to mainland conspecifics.

\section{Notes}

We gratefully acknowledge the financial support of the American Philosophical Society (Penrose Funds 8753). We are also grateful to Dr. Francesca Cuthbert for her encouragement and aid.

\section{References}

Arnold, S. J. (1981a). Behavioral variation in natural populations. I. Phenotypic, genetic, and environmental correlations between chemoreceptive responses to prey in the garter snake, $T$. elegans. Evolution, 35:489-509.

Arnold, S. J. (1981b). Behavioral variation in natural populations. II. The inheritance of a feeding response in crosses between geographic races of the garter snake, T. elegans. Evolution, 35:510-515.

Burghardt, G. M. (1969). Comparative prey-attack studies in newborn snakes of the genus Thamnophis. Behaviour, 33:77-114.

Carpenter, C. C. (1952). Comparative ecology of the common garter snake (Thamnophis s. sirtalis), the ribbon snake (Thamnophis s. sauritus) and the Butler's garter snake (Thamnophis butleri) in mixed populations. Ecol. Monogr., 22:235-258.

Chiszar, D., Taylor, S. V., Radcliffe, C. W., Smith, H. M., and O'Connell, B. (1981). Effects of chemical and visual stimuli upon chemosensory searching by garter snakes and rattlesnakes. $J$. Herpetol., 15:415-423.

Cuthbert, F. (1982). The relationship between body size and garter snake (Thamnophis sirtalis) feeding behavior in a common tern colony (Sterna hirundo). Animal Behavior Society Annual Meeting, 15-19 August 1982, Duluth. 
Fitch, H. S. (1965). An ecological study of the garter snake, Thamnophis sirtalis. U. Kans. Publ. Mus. Nat. Hist., 25:493-564.

Gregory, P. T. (1978). Feeding habits and diet overlap of three species of garter snakes (Thamnophis) on Vancouver Island. Can. J. Zool, , 56:1967-1974.

Hamilton, W. J., Jr. (1951). The food and feeding behavior of the garter snake in New York. Am. Midl. Nat., 46:385-390.

Lagler, K. F., and Salyer, J. C., II. (1945). Influence of availability on the feeding habits of the common garter snake. Copeia, 1945:159-162.

MacArthur, R. H., and Wilson, E. O. (1963). An equilibrium theory of insular zoogeography. Evolu. tion, 17:373-387.

MacArthur, R. H., and Wilson, E. O. (1967). The Theory of Island Biogeography. Princeton, N.J.; Princeton University Press.

Mushinsky, H. R., Hebrard, J. J., and Vodopich, D. S. (1982). Ontogeny of water snake foraging ecology. Ecology, 63:1624-1629. 